\title{
Comparação da eficácia de dois métodos de extração para determinação do perfil lipídico de ácidos graxos do sêmen ovino por meio da Cromatografia Líquida de Alta Eficiência
}

\author{
Comparison of the efficacy of two extraction methods for determination of lipid fatty \\ acids of sheep semen by high performance liquid chromatography
}

\author{
Patrícia Barbosa Salla CARDOSO ${ }^{1}$, Marcílio NICHI ${ }^{1}$, Maria Amélia ZOGNO ${ }^{1}$, Haroldo FUJIWARA ${ }^{1}$, \\ Valquíria Hyppolito BARNABE ${ }^{1}$, Renato Camparanut BARNABE ${ }^{1}$
}

${ }^{1}$ Faculdade de Medicina Veterinária e Zootecnia da Universidade de São Paulo, São Paulo - SP, Brasil

\begin{abstract}
Resumo
A indústria de lã, leite, carne e pele de ovinos tem crescido em importância e novas biotecnologias do sêmen estão sendo estudadas para a elucidação de causas de infertilidade em machos. Sabe-se que danos causados na membrana espermática diminuem a qualidade seminal. Considerando que estas são compostas por uma bicamada de fosfolipídios e que a peroxidação lipídica é causadora de lesão celular, explica-se a importância de estudos sobre os lipídios constituintes do sêmen. A peroxidação lipídica é consequente da reação entre os lipídios e as espécies reativas de oxigênio. Esse quadro pode ser controlado pela presença de antioxidantes no sêmen. O sêmen foi coletado pela técnica da vagina artificial e após análise imediata e mediata, foi separado em duas frações: plasma seminal e pellet de espermatozoide. Seus lipídios foram extraídos por dois métodosbaseados no método Folch, Lesse Stanley modificado diferentes, utilizando clorofórmio e metanol como solventes. Após foram qualificados e quantificados pela especificidade e sensibilidade da Cromatografia Liquida de Alta Eficiência e escolheu-se a melhor extração. A análise estatística dos dados foi realizada através do programa SAS for Windows. O AG saturado predominante no espermatozoide é o mirístico e o AG insaturado predominante é o DHA, em ambas as extrações. No plasma seminal, nos dois métodos, o AG saturado que prevalece é o palmítico e o insaturado é o oleico. Dentre os dois métodos estudados, o que obtivemos melhores resultados na identificação e quantificação dos AG foi a Método 1.
\end{abstract}

Palavras-chave: Sêmen. Ovino. Perfil lipídio. HPLC.Extração.

\begin{abstract}
The sheep industry for wool, milk and meat production is of increasing importance and new technologies for assessment of semen are in course for the elucidation of male infertility causes. It is well known that damage to the sperm membrane decreases semen quality. Considering that sperm membranes are composed by a phospholipid bilayer, and that lipid peroxidation is a major cause of cell damage, studieson the lipid components of semen are relevant. Lipid peroxidation is a consequence of the reaction between lipids and reactive oxygen species. This event may be reduced in the presence of antioxidants in semen. Semen was collected with an artificial vagina and, after sperm evaluation, samples were centrifuged to separate the sample into two fractions: seminal plasma and spermatozoa pellet. Both had their lipids extracted by two different methods based on Folch, Less\& Stanley method modified, using chloroform e methanol as solvents. After the extraction, some esterified fatty acids were qualified and quantified for the sensitivity and specificity to the high performance liquid chromatography in order to determine the most efficient extraction technique in quantitative and qualitative aspects. Statistical analysis was performed using SAS software for Windows. The predominant saturated fatty acid in sperm under these experimental conditions was the myristic and the most abundant insaturated fatty acid in both extractions was DHA. In seminal plasma, in both methods, the prevailing fatty acid is the saturated palmitic and the unsaturated oleic. Among the methods evaluated, we obtained the best results of identification and quantification of fatty acids in Method 1.
\end{abstract}

Keywords: Semen. Sheep. Lipid profile. HPLC. Extraction.

\section{Introdução}

As membranas biológicas são formadas por uma bicamada de fosfolipídios contendo proteínas e atuam como barreira seletivas ${ }^{1}$, assim como nas membranas espermáticas, as quais possuem um papel ativo em
Correspondência para:

Patrícia Barbosa Salla Cardoso

Rua Helio Manzoni, 338 apto 1410 - Gopoúva

Guarulhos - SP; CEP: 07092-070

Email: pbsalla@hotmail.com

Recebido: 29/07/2010

Aprovado: 09/11/2011 
sua capacidade fertilizante, reação acrossômica e fusão do oócito². A composição lipídica da membrana espermática é estabelecida após maturação epididimária do espermatozoide ${ }^{3}$.

Os lipídios apresentam-se de forma assimétrica na membrana espermática, determinando a motilidade, viabilidade e peroxidação lipídica, como relata Bukar et al. ${ }^{4}$. Cerolini et al. ${ }^{5}$ explica que esta composição influencia na congelabilidade do espermatozoide. Há diversos ácidos graxos poli-insaturados (PUFA) na membrana espermática humana, como o ácido docosahexaenoico (DHA) ${ }^{6}$. Em ovinos, o DHA proporciona a fluidez necessária para a fertilização ${ }^{7}$. As aves têm composição de ácidos graxos (AG) semelhante no espermatozoide e no plasma seminal, sendo os ácidos predominantes os esteárico, araquidônico e o docosatetraenoico,como relata Blesbois et al. ${ }^{8}$.

Embora o estresse oxidativo causado pelas espécies reativas de oxigênio (ROS) seja considerado a maior causa de infertilidade em homens, segunda Colagare Marzony ${ }^{9}$, a existência fisiológica de ROS no sêmen é vital para a proliferação, diferenciação espermática ${ }^{10}$, capacitação e reação acrossômica, uma vez, que as ROS são essenciais para causar as modificações funcionais e estruturais na membrana espermática, para que o espermatozoide seja capaz de fertilizar o óvulo, ou seja, o processo de capacitação depende das alterações de permeabilidade da membrana consequente da ação das $\operatorname{ROS}^{11}$.

O espermatozoide é vulnerável ao estresse oxidativo, pois sua membrana é rica em PUFA e seu citoplasma, pobre em antioxidantes ${ }^{12}$, pois há grande perda no momento da maturação, sendo dependente da defesa dos antioxidantes presentes no plasma seminal ${ }^{11}$. O dano causado pelas ROS em desequilíbrio, leva a alterações de morfologia e motilidade, afetando a fluidez,da regulação da espermatogênese, da integridade do DNA, acelera a apoptose da célula germinativa, causa o declínio da concentração espermática associada à infertilidade e deterioração da qualidade seminal e capacidade do espermatozoide sofrer reação acrossômica e fertilizar, por causar danos nos lipídios, aminoácidos, carboidratos, proteínas e no $\mathrm{DNA}^{12}$.

Muitos são os estudos envolvidos com o estresse oxidativo, porém há poucas pesquisas sobre o perfil lipídico do sêmen de animais. Para que seja possível a realização destes trabalhos, os lipídios devem ser extraídos destas amostras para posterior análise e o método de extração de lipídios mais comumente usado é o proposto por Folch, Lesse Stanley ${ }^{13}$, que envolve a utilização de clorofórmio e metanol como solventes, método este utilizado por Hartree e Mann ${ }^{14}$ em estudo com sêmen de carneiros e por Castellini et al. ${ }^{15}$ com sêmen de coelhos.

Para a determinação do perfil lipídico a cromatografia gasosa é a escolhida pelos pesquisadores por estar amplamente difundida, porém é uma técnica que não permite a reutilização da amostra estudada, desvantagem que contribuiu para a substituição pela cromatografia líquida. A Cromatografia Líquida de Alta Eficiência (CLAE ou HPLC) é uma análise não destrutível, além de ser mais sensível na identificação da amostra ${ }^{16}$. Castellini et al. ${ }^{15}$, após extrair lipídios do sêmen de coelhos, utilizou a CLAE para analisar suas amostras.

Devido à importância da composição de AG no sêmen, os quais fazem parte de lipídios complexos da membrana celular, como fosfatidilcolinas. Este estudo visou à extração desta classe de componentes do plasma seminal e da membrana espermática,comparando duas extrações diferentes, ambas baseadas no método Folch, Lees e Stanley ${ }^{13}$ modificado.O extrato lipídico obtido foi qualificado e quantificado pela CLAE e assim escolhida a melhor extração.

\section{Material e Método}

Realizou-se, na Faculdade de Medicina Veterinária e Zootecnia da Universidade de São Paulo, dez coletas aleatórias de sêmen, no período de 12 meses, com o intuito de excluir a interferência sazonal. Sete carneiros da raça Santa Inês e mestiços, de três a cinco anos de 
idade, mantidos sob as mesmas condições de manejo e alimentação, foram considerados saudáveis após avaliação da integridade dos testículos, epidídimo, sistema locomotor, sanidade geral e escore corporal.

O sêmen foi coletado pela técnica da vagina artificial contendo tubo coletor graduado em mililitros, previamente aquecido a $37^{\circ} \mathrm{C}$, protegido com tecido evitando o contato com a luz e o choque térmico, danosos aos espermatozoides ${ }^{17}$. Após coleta, o tubo foi mantido em banho-maria a $37^{\circ} \mathrm{C}$ até o processamento da amostra.

O sêmen foi avaliado quanto à motilidade, vigor e turbilhonamento, de acordo com os parâmetros seminais propostos pelo CBRA $^{18}$ e somente 20 amostras respeitavam tais parâmetros, as quais foram respectivamente separadas para extração pelo Método $1 \mathrm{e}$ pelo Método 2.

O material coletado foi centrifugado a $8000 \mathrm{xg}$ por 15 minutos, separando a amostra em duas alíquotas: $\mathrm{o}$ plasma seminal e pellet de espermatozoides, as quais foram estocadas separadamente em microtubos de centrifugação de $2 \mathrm{~mL}$ (Eppendorf ${ }^{\circledast}$ ) e armazenados em freezer comum.Como resultado, foram obtidas para a extração lipídica: 20 amostras de plasma seminal e 20 amostras de pellet de espermatozoide. Destas amostras, já separadas, extraiu-se $10 \mu \mathrm{L}$ de plasma seminal e $20 \mathrm{mg}$ do pellet de espermatozoide dos diferentes microtubos, resultando em 40 amostras no total para cada método, ambos descritos a seguir.

\section{Extração de Lipídios - Método 1}

Dois microtubos de centrifugação foram devidamente identificados, sendo que no microtubo 1 , colocou-se $10 \mu \mathrm{L}$ de plasma seminal ou $20 \mathrm{mg}$ do pellet de espermatozoide, que foram homogeneizados com $400 \mu \mathrm{L}$, por 20 minutos. Após centrifugação a $700 \mathrm{xg}$ por 10 minutos, em temperatura ambiente, o sobrenadante (aproximadamente $200 \mu \mathrm{L}$ ) foi transferido para o microtubo 2, no qual foi adicionado $50 \mu \mathrm{L}$ de solução aquosa de cloreto de potássio a $0,88 \%$, visando à eliminação das impurezas. A mistura foi homoge- neizada e centrifugada a $700 \mathrm{xg}$ por 10 minutos, para separação das amostras. O sobrenadante (aproximadamente $150 \mu \mathrm{L}$ ) foi desprezado com o auxílio de uma pipeta e ao restante foi adicionado $25 \mu \mathrm{L}$, sem misturar o conteúdo. A fração superior foi desprezada por aspiração e a fração inferior submetida à secagem com vapor de nitrogênio e armazenada em freezer comum.

\section{Extração de Lipídios - Método 2}

Novamente, dois microtubos de $2 \mathrm{~mL}$ foram identificados. No microtubo 1 , foram adicionados $10 \mu \mathrm{L}$ de plasma seminal ou 20mg do pellet de espermatozoide, seguido da adição de $1 \mathrm{~mL}$ de metanol para ser homogeinização por vórtex. Adicionou-se, então $1 \mathrm{~mL}$ de clorofórmio e $0,4 \mathrm{~mL}$ de água MiliQ, e novamente foi submetido à homogeneização por vórtex. Houve a formação de um halo branco entre as fases orgânica e aquosa. Aspirou-se $1 \mathrm{~mL}$ da fase inferior com o auxílio de uma pipeta, transferindo-a para o microtubo 2 , o qual foi mantido em gelo. Ainda no primeiro microtubo, fez-se uma segunda extração adicionando $0,5 \mathrm{~mL}$ de metanol, $0,5 \mathrm{~mL}$ de clorofórmio e água MiliQ até completar o volume do tubo. Essa segunda mistura foi submetida à homogeinização por vórtex. Sua fração superior foi desprezada por aspiração e o restante misturado ao microtubo 2, no qual foi adicionado $0,5 \mathrm{~mL}$ da Mistura de Folch, Lees e Stanley ${ }^{16}$ à base de Clorofórmio: Metanol: Água (3:48:47) e homogeinizado com vórtex.. A fração superior foi desprezada por aspiração e o restante submetido à secagem por vapor de nitrogênio e armazenado em freezer comum.

\section{Saponificação}

As amostras extraídas pelos dois métodos e armazenadas no freezer foram ressuspendidas em $1 \mathrm{~mL}$ de $\mathrm{NaOH}$ :Metanol (1:1)e submetidas à homogeneização com vórtex, e então transferidas para um tubo de vidro previamente lavado com solução de potassa (metanol $+\mathrm{KOH} 2 \%)$. O tubo foi vedado e incubado por duas horas em banho-maria a $37^{\circ} \mathrm{C}$. Posteriormente, adicionou-se $2 \mathrm{~mL}$ de $\mathrm{HCl}$ e o tubo foi submetido à homogeneização por vórtex. Adicionou-se $1 \mathrm{~mL}$ de 
Hexano e repetiu-se o procedimento de homogeneização. A camada superior formada, que corresponde à fração lipídica, foi recuperada com o auxílio de uma pipeta e transferida a um novomicrotubo. Esta etapa foi repetida mais uma vez, no mesmo tubo de vidro, e o sobrenadante colocado no mesmo microtubo, para secagem no fluxo de nitrogênio e posterior derivatização, conforme Martins et al. ${ }^{16}$.

\section{Derivatização e Cromatografia}

$\mathrm{Na}$ derivatização, ressuspenderam-se as amostras secas em $100 \mu \mathrm{L}$ de Acetonitrila (ACN) e estas foram passadas no vórtex. Após, adicionaram-se $20 \mu \mathrm{L}$ de bromometilmetoxicumarim dissolvido em ACN e 20 $\mu$ Lde 18-crown-6-ether $\left(\mathrm{C}_{2} \mathrm{H}_{4} \mathrm{O}\right)_{6}$ dissolvidos em ACN em $40 \mu \mathrm{L}$ de amostra em tubo redutor de volume vedado, homogeneizado com vórtex e incubado a $65^{\circ} \mathrm{C}$ por 15 minutos em banho seco e então analisada pelo HPLC (MARTINS et al. ${ }^{16}$ ).

Foi utilizado um HPLC da Shimazu com fluxo de $1 \mathrm{~mL}$ por minuto, fase móvel composta por $\mathrm{A}=\mathrm{ACN}$ (77\%) e B= água (23\%), com coluna C8 Supelco de fase reversa com sílica mantida a temperatura ambiente, pressão de $60 \mathrm{Kg} / \mathrm{cm}^{2}$ e detector de fluorescência com os respectivos comprimentos de onda de excitação e de emissão, 325nm e 395nm. Usaram-se como padrões os seguintes AG derivatizados: Caproico; Caprílico; Margárico; Oleico; Esteárico; Linoleico; Linolênico; Araquidônico; Eicosapentaenoico (EPA); e o DHA.

Todos os solventes, reagentes e padrões utilizados são Sigma-Aldrich ${ }^{\circledR}$ (Sigma-Aldrich Corp, St. Louis, MO, EUA).

Os dados foram analisados pelo programa SAS System for Windows (2000) e o aplicativo Guided Data Analisys foi utilizado visando testar os dados quanto à normalidade dos resíduos e homogeneidade das variâncias. A análise paramétrica foi realizada por meio do teste t de Student. Para descrição dos resultados, empregaram-se as médias e os erros padrões (média \pm erro padrão da média) dos dados originais e seus níveis de significância $(\mathrm{P})$, quando obedecessem às premissas de normalidade e homogeneidade. Todas as variáveis respostas avaliadas obedeceram às premissas.Considerou-se o nível de significância 5\%. As variáveis classificatórias utilizadas foram matriz (espermatozoide vs. plasma seminal) e método de extração dos lipídeos (Método 1 vs. Método 2).

\section{Resultados e Discussão}

Verificou-se que o Método 1 é melhor em relação ao 2, levando-se em consideração a quantidade recuperada e a presença de diferentes $A G$, já que o Método 2 não identificou os seguintes AG: caproico, caprílico, cáprico e margárico. Não foi possível observar por meio de nenhum dos métodos de extração a presença do ácido graxo EPA e do linolênico. Este fato pode ter ocorrido devido à condição de armazenagem prolongada das amostras em gelo no Método 2, em concordância com Lahnsteiner et al. ${ }^{19}$, que observaram maior quantidade de lipídios em amostras frescas em relação às amostras congeladas. Além disso, há maior concentração de AG totais nos espermatozoides utilizando-se o Método 1, em relação ao Método $2(339,62 \pm 53,37$ vs. 157,86 \pm 44,55, respectivamente, Tabela 1). Provavelmente, o tempo de ação de metanol:clorofórmio na amostra utilizando-se o Método 2 não foi suficiente para extrair quantidade representativa de AG, considerando-se que no Método1 foi utilizado tempo de incubação de 20 minutos e no método de extração 2 , a incubação é realizada por apenas 1 minuto.

Efeito dos métodos de extração sobre o perfil de ácidos graxos no plasma seminal

Não houve diferença entre AGs saturados e insaturados no plasma seminal comparando-se os dois Métodos (Figura 1), o que sugere que os mesmos sejam equivalentes para se determinar a proporção de $A G$ em plasma seminal ovino.

Em ambos os Métodos, como esperado, observou-se maior quantidade de AG totais no espermatozoide, em relação ao plasma seminal. Barrios et al. ${ }^{20}$ 
Tabela 1 - Efeito dos métodos de extração (extração $1 \mathrm{e}$ extração 2) sobre a concentração (ng/g) dos AG dos espermatozoides avaliados através da área dos picos obtidos peloHPLC em amostras espermáticas de carneiros - São Paulo 2008 a 2009

\begin{tabular}{cccc}
\hline & Extração 1 & Extração 2 & $\mathrm{P}$ \\
\hline Caproico & $0,01 \pm 0,01$ & 0 & 0,3739 \\
Caprílico & $0,3 \pm 0,1$ & 0 & 0,0392 \\
Cáprico & $0,04 \pm 0,04$ & 0 & 0,3739 \\
Láurico & $4,77 \pm 1,52$ & $3,35 \pm 1,58$ & 0,5331 \\
Mirístico & $31,21 \pm 7,76$ & $14,47 \pm 5,94$ & 0,1253 \\
Palmítico & $54,43 \pm 5,81$ & $24,02 \pm 4,89$ & 0,0039 \\
Margárico & $0,09 \pm 0,09$ & 0 & 0,3739 \\
Esteárico & $21,12 \pm 2,47$ & $7,92 \pm 2,48$ & 0,0055 \\
EPA & 0 & 0 & - \\
Linolênico & 0 & 0 & - \\
DHA & $168,18 \pm 28,76$ & $81,58 \pm 20,78$ & 0,0405 \\
Araquidônico & $12,35 \pm 1,90$ & $5,54 \pm 1,81$ & 0,0317 \\
Palmitoleico & $3,8 \pm 0,95$ & $1,37 \pm 0,96$ & 0,1096 \\
Linoleico & $35,15 \pm 8,84$ & $16,53 \pm 5,98$ & 0,1192 \\
Oleico & $8,7 \pm 1,09$ & $3,08 \pm 1,30$ & 0,0173 \\
TOTAL & $339,62 \pm 53,37$ & $157,86 \pm 44,55$ & 0,0309 \\
\hline
\end{tabular}

relatam que o plasma seminal melhora a viabilidade do espermatozoide em ovinos, por ser uma mistura complexa que contém proteínas que protegem o espermatozoide de lesões associadas ao estresse térmico e oxidativo. Esta mistura de substâncias pode prejudi- car a extração dos AG totais do plasma seminal, sendo necessárias mais lavagens.

\section{Ácidos graxos no espermatozoide e no plasma se- minal - Método 1}

Houve maior concentração de AG totais na amostra de espermatozoides, em relação ao plasma seminal $(339,62 \pm 53,37$ vs. $27,09 \pm 7,61$, respectivamente, Tabela 2). Dado explicado pela constituição biológica do plasma seminal, como relatou Martins et al. ${ }^{21}$ ao determinarem que proteínas zsão as biomoléculas predominantes no plasma seminal de bodes. Os espermatozoides possuem maiores concentrações de DHA, em relação ao plasma seminal $(168,18 \pm 28,76$ vs. $6,38 \pm 2,51$, respectivamente, Tabela 2). Além disso, o DHA representa quase 50\% dos AG totais em espermatozoides. Em concordância com estes dados, Aksoyet al. ${ }^{22}$ obtiveram altas concentrações de DHA no espermatozoide de homens normozoospérmicos, o que explica a susceptibilidade da célula espermática ao estresse oxidativo. O DHA é indispensável para manter a fluidez,

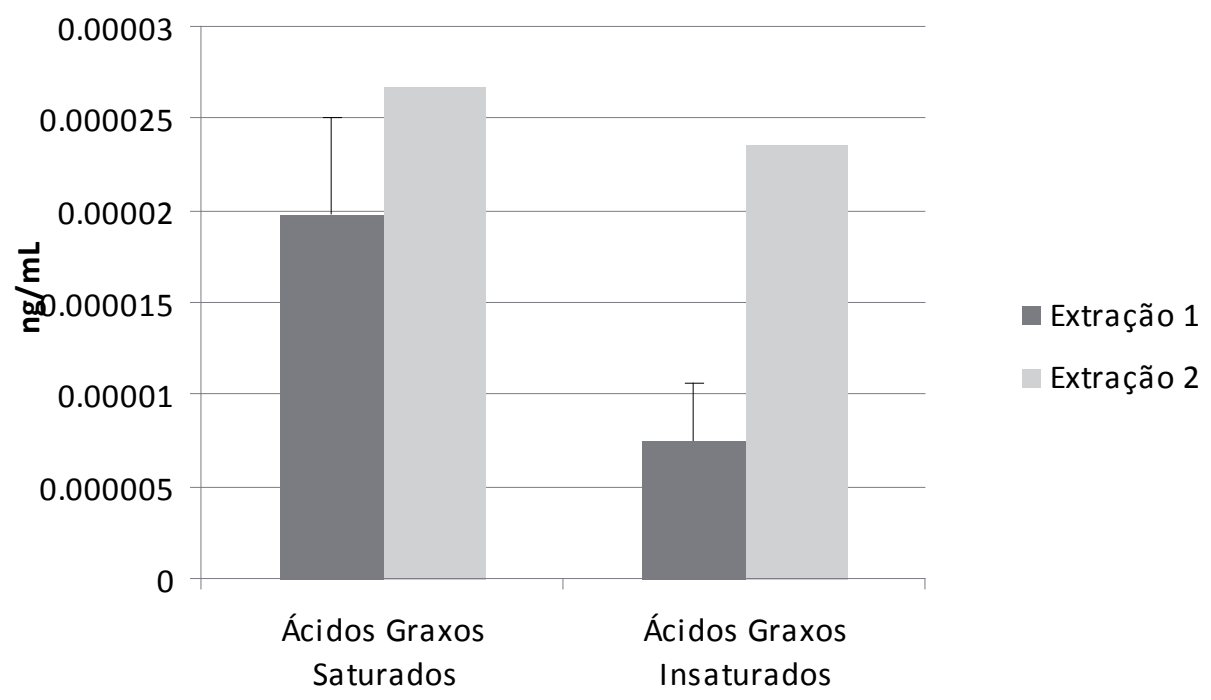

Figura 1 -Efeito dos métodos de extração (extração 1 e extração 2) sobre a concentração (ng/ $\mathrm{ml}$ ) do total de ácidos graxos saturados e insaturados do plasma seminal, avaliado através da área dos picos obtidos pela Cromatografia Líquida de Alta Performance em amostras espermáticas de carneiros - São Paulo - 2008 a 2009 
Tabela 2 - Efeito da matriz (espermatozoide e plasma seminal) sobre a concentração (ng/g e ng/ml, respectivamente) dos $\mathrm{AG}$ avaliados através da área dos picos obtidos peloHPLC em amostras espermáticas de carneiros, utilizando o método de extração 1 - São Paulo - 2008 a 2009

\begin{tabular}{cccc}
\hline & Espermatozoide & Plasma Seminal & $\mathrm{P}$ \\
\hline Caproico & $0,01 \pm 0,01$ & 0 & 0,3739 \\
Caprílico & $0,3 \pm 0,1$ & 0 & 0,0392 \\
Cáprico & $0,04 \pm 0,04$ & 0 & 0,3739 \\
Láurico & $4,77 \pm 1,52$ & $2,20 \pm 0,9$ & 0,2176 \\
Mirístico & $31,21 \pm 7,76$ & $1,53 \pm 0,56$ & 0,0185 \\
Palmítico & $54,43 \pm 5,81$ & $11,15 \pm 2,77$ & 0,0005 \\
Margárico & $0,09 \pm 0,09$ & 0 & 0,3739 \\
Esteárico & $21,12 \pm 2,47$ & $4,88 \pm 1,34$ & 0,0011 \\
EPA & 0 & 0 & - \\
Linolênico & 0 & 0 & - \\
DHA & $168,18 \pm 28,76$ & $6,38 \pm 2,51$ & 0,0048 \\
Araquidônico & $12,35 \pm 1,90$ & 0 & 0,0029 \\
Palmitoleico & $3,8 \pm 0,95$ & 0 & 0,0161 \\
Linoleico & $35,15 \pm 8,84$ & $0,39 \pm 0,39$ & 0,0170 \\
Oleico & $8,7 \pm 1,09$ & $0,76 \pm 0,45$ & 0,0007 \\
TOTAL & $339,62 \pm 53,37$ & $27,29 \pm 7,61$ & 0,0039 \\
\hline
\end{tabular}

motilidade e reação acrossomal ${ }^{23}$. Embora o ácido araquidônico não tenha sido identificado no plasma, este resultado foi inesperado, pois sua presença atua na motilidade espermática e na reação acrossomal, conforme apontado por Hossain et al. ${ }^{24}$.
Dentre os AG saturados e insaturados, há maior concentração no espermatozoide, em relação ao plasma seminal, no Método $1(111,96 \pm 13,94$ e 227,66 \pm 40,23 vs. $19,76 \pm 5,22$ e 7,53 $\pm 3,13$, respectivamente, Figura 2), dado relacionado à constituição do plasma seminal, além de a célula espermática ser constituída de fosfolipídios principalmente, fator que torna o gameta ainda mais susceptível ao efeito das ROS.

Houve maior porcentagem de DHA no espermatozoide, em relação ao plasma seminal $(49,03 \pm 1,97 v$ s. $25,75 \pm 7,72$, respectivamente, Tabela 3). Entretanto, houve maior porcentagem do AG palmítico no plasma seminal, em relação ao espermatozoide (41,78 \pm 1,56 vs. $16,70 \pm 1,15$, respectivamente, Tabela 3), em concordância com Khosrowbeygi e Zarghami² que observaram maior quantidade do ácido palmítico em homens normozoospérmicos.

Ácidos graxos no espermatozoide e no plasma seminal - Método 2

Mesmo não sendo possível realizar a estatística, os resultados mostraram semelhança entre a composição de AG no espermatozoide e no plasma seminal,

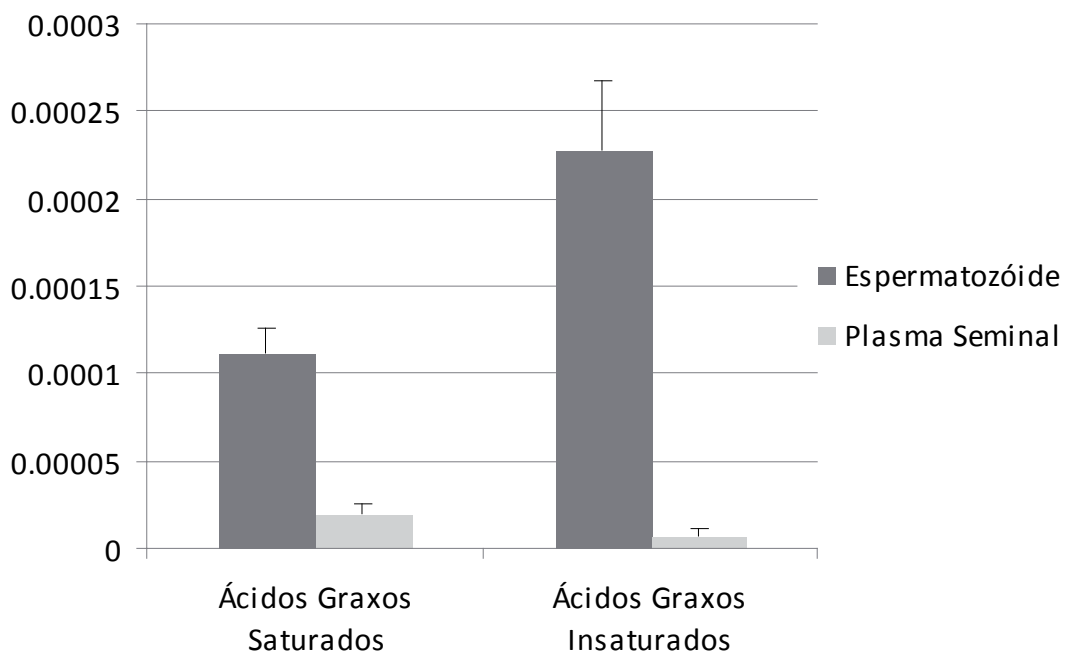

Figura 2 - Efeito da matriz (espermatozoide e plasma seminal) sobre a concentração (ng/g e ng/ml, respectivamente) do total de ácidos graxos saturados e insaturados avaliados através da área dos picos obtidos pela Cromatografia Líquida de Alta Performance em amostras espermáticas de carneiros, utilizando o método de extração 1 - São Paulo - 2008 a 2009 
Tabela 3 - Efeito da matriz (espermatozoide e plasma seminal) sobre a porcentagem dos AG avaliados pelo HPLC em amostras espermáticas de carneiros, utilizando o método de extração 1 - São Paulo - 2008 a 2009

\begin{tabular}{cccc}
\hline & Espermatozoide & Plasma Seminal & $\mathrm{P}$ \\
\hline Caproico (\%) & $0,003 \pm 0,003$ & 0 & 0,3739 \\
Caprílico(\%) & $0,11 \pm 0,04$ & 0 & 0,0719 \\
Cáprico(\%) & $0,02 \pm 0,02$ & 0 & 0,3739 \\
Láurico (\%) & $1,37 \pm 0,31$ & $7,37 \pm 3,59$ & 0,1932 \\
Mirístico(\%) & $9,21 \pm 1,44$ & $4,59 \pm 1,57$ & 0,0671 \\
Palmítico (\%) & $16,70 \pm 1,15$ & $41,78 \pm 1,56$ & $<0,0001$ \\
Margárico(\%) & $0,04 \pm 0,04$ & 0 & 0,4071 \\
Esteárico (\%) & $6,6 \pm 0,74$ & $17,46 \pm 2,07$ & 0,0010 \\
EPA (\%) & 0 & 0 & 0 \\
Linolênico (\%) & 0 & 0 & 0 \\
DHA (\%) & $49,03 \pm 1,97$ & $25,75 \pm 7,72$ & 0,0529 \\
Araquidônico (\%) & $3,68 \pm 0,2$ & 0 & $<0,0001$ \\
Palmitoleico(\%) & $1,05 \pm 0,14$ & 0 & 0,0016 \\
Linoleico (\%) & $9,71 \pm 1,86$ & $0,85 \pm 0,85$ & 0,0055 \\
Oleico (\%) & $2,45 \pm 0,10$ & $2,17 \pm 1,26$ & 0,8384 \\
\hline
\end{tabular}

havendo apenas o DHA em maior concentração nos célula espermática, em relação ao plasma seminal $(81,58 \pm 20,78$ vs. $0,34 \pm 0$, respectivamente, Tabela 4), o qual corresponde a mais de $50 \%$ dos AG totais. O DHA é a mais importante PUFA do espermatozoide, sendo um dos principais alvos do estresse oxida-

Tabela 4 - Efeito da matriz (espermatozoide e plasma seminal) sobre a concentração (ng/g e ng/ml, respectivamente) dos AG avaliados através da área dos picos obtidos peloHPLC em amostras espermáticas de carneiros, utilizando o método de extração 2 - São Paulo - 2008 a 2009

\begin{tabular}{cccc}
\hline & Espermatozoide & Plasma Seminal & P \\
\hline Caproico & 0 & 0 & - \\
Caprílico & 0 & 0 & - \\
Cáprico & 0 & 0 & - \\
Láurico & $3,35 \pm 1,58$ & $1,32 \pm 0$ & - \\
Mirístico & $14,47 \pm 5,94$ & 0 & - \\
Palmítico & $24,02 \pm 4,89$ & $2,10 \pm 0$ & - \\
Margárico & 0 & 0 & - \\
Esteárico & $7,92 \pm 2,48$ & $1,54 \pm 0$ & - \\
EPA & 0 & 0 & - \\
Linolênico & 0 & 0 & - \\
DHA & $81,58 \pm 20,78$ & $0,34 \pm 0$ & - \\
Araquidônico & $5,54 \pm 1,81$ & 0 & - \\
Palmitoleico & $1,37 \pm 0,96$ & 0 & - \\
Linoleico & $16,53 \pm 5,98$ & $0,95 \pm 0$ & - \\
Oleico & $3,08 \pm 1,30$ & $3,09 \pm 0$ & - \\
TOTAL & $157,86 \pm 44,55$ & $9,36 \pm 0$ & \\
\hline
\end{tabular}

tivo, além do DNA como relata Nichi ${ }^{12}$. Aksoy et al. ${ }^{22}$ observaram altas concentrações de DHA em homens normozoospérmicos em relação aos outros grupos com afecções, o que sugere sua função crucial na fluidez do espermatozoide e na habilidade fertilizante.

Embora não seja possível a realização de estatística, há maior porcentagem de DHA na amostra de espermatozoides, em relação ao plasma seminal $(53,07 \pm$ 2,96 vs. 3,64 \pm 0 , respectivamente, Tabela 5) e maior porcentagem do AG oleico no plasma seminal em relação ao espermatozoide $(33,36 \pm 0$ vs. 1,63 $\pm 0,42$, respectivamente, Tabela 5).

Em relação ao Método 2, a estatística foi prejudicada, uma vez que a maior parte dos valores obtidos forma iguais a zero, logo, podemos considerar que o Método 2 não foi capaz de extrair AG suficiente para que o aparelho detecte, ou pode ter ocorrido alguma contaminação durante o processo, levando à leitura errada das amostras ${ }^{25}$.

\section{Conclusão}

Conclui-se que a composição de AG do espermatozoide e a do plasma seminal são semelhantes, embora

Tabela 5 - Efeito da matriz (espermatozoide e plasma seminal) sobrea porcentagem dos AG avaliados pela HPLC em amostras espermáticas de carneiros, utilizando o método de extração 2 - São Paulo - 2008 a 2009

\begin{tabular}{cccc}
\hline & Espermatozoide & Plasma Seminal & P \\
\hline Caproico (\%) & 0 & 0 & - \\
Caprílico(\%) & 0 & 0 & - \\
Cáprico(\%) & 0 & 0 & - \\
Láurico (\%) & $1,76 \pm 0,49$ & $7,11 \pm 0$ & - \\
Mirístico(\%) & $8,45 \pm 0,93$ & 0 & - \\
Palmítico (\%) & $16,57 \pm 1,33$ & $11,32 \pm 0$ & - \\
Margárico(\%) & 0 & 0 & - \\
Esteárico (\%) & $4,98 \pm 0,57$ & $8,31 \pm 0$ & - \\
EPA (\%) & 0 & 0 & - \\
Linolênico (\%) & 0 & 0 & - \\
DHA (\%) & $53,07 \pm 2,96$ & $1,83 \pm 0$ & - \\
Araquidônico (\%) & $3,34 \pm 0,17$ & 0 & - \\
Palmitoleico(\%) & $0,54 \pm 0,33$ & 0 & - \\
Linoleico (\%) & $9,65 \pm 1,75$ & $5,12 \pm 0$ & \\
Oleico (\%) & $1,63 \pm 0,42$ & $16,64 \pm 0$ & \\
\hline
\end{tabular}


alguns AG de baixa concentração (cáprico, caprílico e caproico) não tenham sido identificados no plasma seminal. O AG saturado predominante no espermatozoide é o mirístico e o insaturado é o DHA, extraídos por ambos os métodos. No plasma seminal, nos dois métodos, o AG saturado que prevalece é o palmíti-

\section{Referências}

1. COOPER, G. M. The cell: a molecular approach. Washington: ASM Press, 1996.673 p.

2.KHOSROWBEYGI, A.; ZARGHAMI, N. Fatty acid composition of human spermatozoa and seminal plasma levels of oxidative stress biomatkers in subfertile males. Prostaglandins, Leukotrienes and Essencial Fatty Acids, v. 77, n. 2, p. 117-121, 2007.

3. GRIZARD, G.; SION, B.; BAUCHART, D.; BOUCHER, D. Separation and quantification of cholesterol and major phospholipid classes in human semen by high-performance liquid chromatography and light-scattering detection. Journal of Chromatography B Biomedical Sciences and Applications, v. 740, n. 1, p. 101-107, 2000.

4. BUKAR, M. N.; ATESSAHIN, A.; VARISH, O.; YUCE, A.; TEKIN, N.; AKCAY, A. The influence of trehalose, taurine, custeamine and hyaluronan on ram semen. Microscopic and oxidative stress parameters after freeze-thawing process. Theriogenology, v.67, n.5, p.1060-1067, 2007.

5. CEROLINI, S.; MALDJIAN, A.; PIZZI, F.; GLIOZZI, T. M. Changes in sperm quality and lipid composition during cryopreservation of boar semen. Reproduction, v. 121, n. 3, p. 395-401, 2001.

6. OLLERO, M.; POWERS, R. D.; ALVAREZ, J. G. Variation of decosahexanoic acid content in subsets of human spermatozoa at different stages of maturation: implications for sperm lipoperoxidative damage. Molecular Reproduction and Development, v. 55, n. 1, p. 326-334, 2000

7. HATAMOTO, L. K.; SOBRINHO, C. A. B.; NICHE, M.; BARNABE, V. H.; BARNABE, R. C.; CORTADA, C. N. M. Effects of dexamethasone treatment (to mimic stress) and Vitamin E oral supplementation on the spermiogram and seminal plasma spontaneous lipid peroxidation and antioxidant enzyme activities in dogs. Theriogenology, v. 66, n. 6-7, p. 1610-1614, 2006.

8. BLESBOIS, E.; LESSIRE, M.; GRASSEAU, I.; HALLOUIS, J.M.; HERMIER, D. Effect of dietary fat on the fatty acid composition and fertilizing ability of fowl semen. Biology of Reproduction, v. 56, n. 1, p. 1216-1220, 1997.

9. COLAGAR, A. H.; MARZONY, E. T. Ascorbic acid in human seminal plasma: determination and its relationship to sperm quality. Journal of Clinical Biochemistry and Nutrition, $v$ 45, n. 2, p. 144-149, 2009.

10.SHAMZI, M. B.; VENKATESH, S.; TANWAR, P.; SHARMA, R. K.; DHWAN, A.; KUMAR, R.; GUPTA, N. P.; MALHOTRA, N.; SING, N.; MITTAL, S.; DADA, R. DNA integrity and semen quality in men with low seminal antioxidant levels. MutationResearch, v. 665, n. 1-2, p. 29-36, 2009.

11.CARVALHO, O. F.; FERREIRA, J. D. J.; SILVEIRA, N. A.; FRENEAU, G. E. Efeito oxidativo do óxido nítrico e infertilidade no macho. Jornal Brasileiro de Patologia e co e o insaturado é o oleico. Ainda se conclui que o Método 1 é mais efetivo para a extração dos lipídios destinados à identificação e na quantificação dos AG, em relação ao Método 2, que possui muitas etapas de lavagens e com volumes muito altos de solventes, aumentando os riscos de contaminação no processo ${ }^{25}$.

Medicina Laboratorial, v. 38, n. 1, p. 33-38, 2002.

12. NICHI, M. Sistemas de produção enzimática e níveis de peroxidação espontânea dos lipídios seminais de touros zebuínos e taurinos criados a campo na região de Dourados, MS. 2003. 101f. Dissertação (Mestrado) - Faculdade de Medicina Veterinária e Zootecnia, Universidade de São Paulo, São Paulo, 2003.

13.FOLCH, J.; LEES, M.; STANLEY, G. H. A simple method for the isolation and purification of total lipid from animal tissues. Journal of Biology and Chemistry, v. 226, n. 1, p. 497-509, 1957.

14.HARTREE, E. V.; MANN, T. Phospholipids in ram semen: metabolism of plasmalogen and fatty acids. Bichemical Journal, v.80, n.3, p.464-476, 1961.

15.CASTELLINI, C.; CARDINALI, R.; DAL BOSCO, A.; MINLLI, A.; CAMICI, O. Lipid composition of the main fractions of rabbit semen. Theriogenology, v.65, n.4, p.703-712, 2006.

16. MARTINS, E. F.; TORRES, R. P.; MALUF, L. M. P.; FILHO, J. M.; NISHIYAMA, A.; PERES, C. M.; MIYOSAKA, C. K. Análise qualitativa e quantitativa de ácidos graxos por cromatografia. In: CURI, R. POMPÉIA, C.; MIYOSAKA, C. K.; PROCOPIO, J. Entendendo a gordura: os ácidos graxos. São Paulo: Manole, 2002. 580 p.

17.GRANADOS, L. B. C.; DIAS, A. J. B.; SALES, M. P. Aspectos gerais da reprodução de caprinos e ovinos. Campos de Goytacazes - RJ: [s.n], 2006. 54 p. Projeto PROEX/UENF.

18. Colégio Brasileiro de Reprodução Animal. Manual para exame andrológico e avaliação de sêmen animal. 2 ed. Belo Horizonte: CBRA, 1998. 53p.

19.LAHNSTEINER, F.; MANSOUR, N.; McNIVEN, M. A.; RICHARDSON, G. F. Fatty acids of rainbow trout (Oncorhynchusmykiss) semen: Composition and effects on sperm functionality. Aquaculture, v. 298, n.1-2, 16, p.118-124, 2009.

20.BARRIOS, B.; PEREZ-PÉ, R.; GALLEGO, M.; TATO, A.; OSADA, J.; MUIÑO-BLANCO, T.; CEBRIAN-PEREZ, J. A. Seminal plasma proteins revert the cold-shock damage on ram sperm membrane. Biology of Reproduction, v.63, p.15311537,2000 .

21.MARTINS, L. F.; PEREIRA, M. C. B.; GUIMARÃES, J. D.; COSTA, E. P.; SILVEIRA, T. S.; TORRES, C. A. A.; RODRIGUES, M. T.; BRAZ, V. B. Avaliação espermática e da concentração de proteínas solúveis no plasma seminal de bodes da raça Alpina em regime de monta controlada. RevistaBrasileira de Zootecnia, v. 35, n. 4, p. 1653-1659, 2006.

22. AKSOY, Y.; AKSOY, H.; ALTINKAYNAK, K.; AYDIN, H. R.; OZKAN, A. Sperm fatty acid composition in subfertile men. Prostaglandins, Leukotrienes and Essencial Fatty Acids, v. 75, n. 2, p. 75-79, 2006. 
23. ROOKE, J. A.; SHAO, C. C.; SPEAKE, B. K. Effects of feeding tuna oil on the lipid composition of pig spermatozoa and in vitro characteristics of semen. Reproduction, v. 121, n. 6, p. 315-322, 2001.

24.HOSSAIN, S.; TAREK, K. M. A.; HAMMANO, K. I.; TSUJII, H. Effect of fatty acids on boar sperm motility viability and acrosome reaction. Reproductive Medicine and Biology, v. 6, n. 4, p. 235-239, 2008

25.TANAMATI, C.; OLIVEIRA, C. C.; VISENTAINER, J. V.; MATSUSHITA, M.; SOUZA, N. E. Comparative study of total lipids in beef using chlorinated solvent and low toxicity solvents methods. JAOCS, v. 82, n. 6, p. 1 - 5, 2005. 